\title{
Quality of life of patients with diabetes mellitus type \\ man-made disaster influencing in Ukraine
}

Iryna Vlasenko' (PhD), Tamara Germanyuk² (DM, professor), Tetana Ivko² (PhD) 'Shupik National Medical Academy of Postgraduate Education, Kiev, Ukraine.

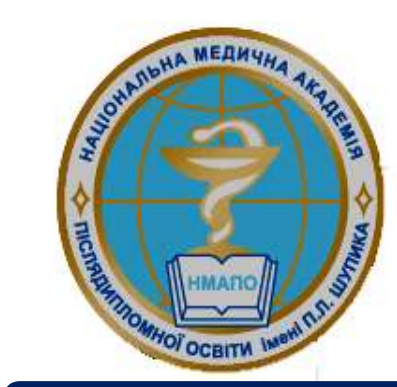

${ }^{2}$ National Pirogov Memorial Medical University, Vinnytsia, Ukraine

vlasenkoiryna5@gmail.com,

germanyuk_tamara@mail.ru, ivkot@e-mail.ua

\section{Background}

Diabetes mellitus (DM) is a global medical and social problem in the world today. In Ukraine, officially registered 1.3 million patients with DM, but according to different sources, the actual number of patients with DM is three times more. Most of them are patients with DM type 2. DM type 2 often has no symptoms and is detected only after 5 to 10 years when the complications already exist. According to the international recommendations, the key aspects of improving the patients' quality of life (QOL) with DM are: early detection, the treatment order of adequate therapy and careful monitoring of the disease. But the environment has a significant impact on QOL.

\section{Aim}

The aim of the study was investigation of the level of QOL of the patients with type 2 DM (T2DM) before and after the treatments with different monotherapy.

\section{Methodology}

For investigation of 300 patients with DM type 2 which received therapy regimes with metformin, glimepiride and gliclazide were selected. These patients were treated in the endocrinology clinics of Podolsky region of Ukraine in 20162017 (Vinnytsia, Khmelnitsky, Ternopil regions). The patients were examined on the following parameters: age, sex, duration of T2DM, body mass index, the average fasting plasma glucose, level of QOL before and after prescribing the treatment, prescribed therapy. All patients were treated with oral antidiabetic drugs only. The patients' QOL was determined by visual analogue scale adapted by European questionnaire of quality of life EuroQol-5D. Information about QOL of the patients before and after the treatment were collected and compared.

\section{Results}

It was found that age of patients ranged from 30 to 60 years: $30-40-17 \%$ (51 patient), 40-50 - 29\% (87 patients), 50-60 $54 \%$ (162 patients). Among the patients, women comprised $51 \%$ (153 patients), men - 49\% (147 patients).

\section{Age of patients with DM 2 type}

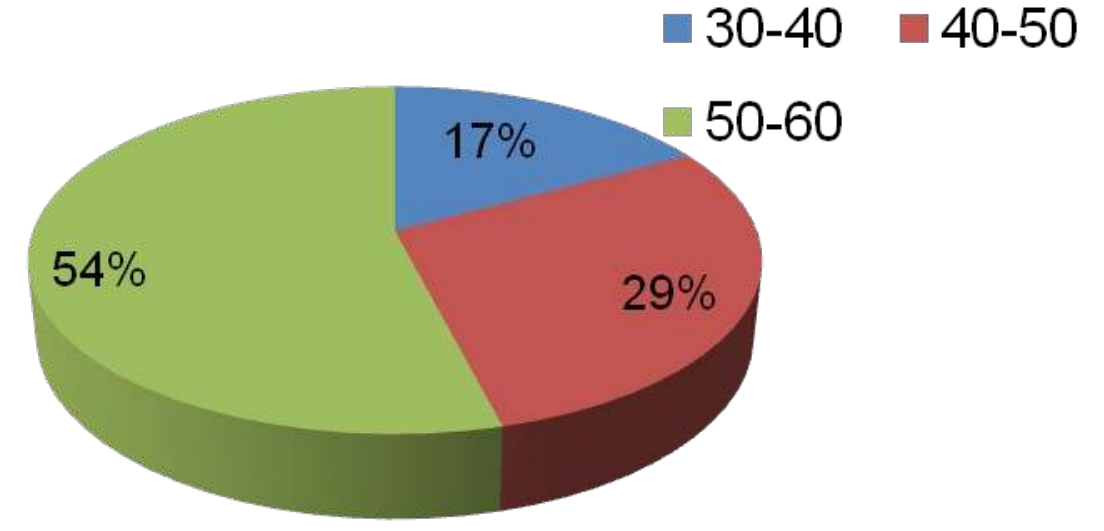

Human sex ratio

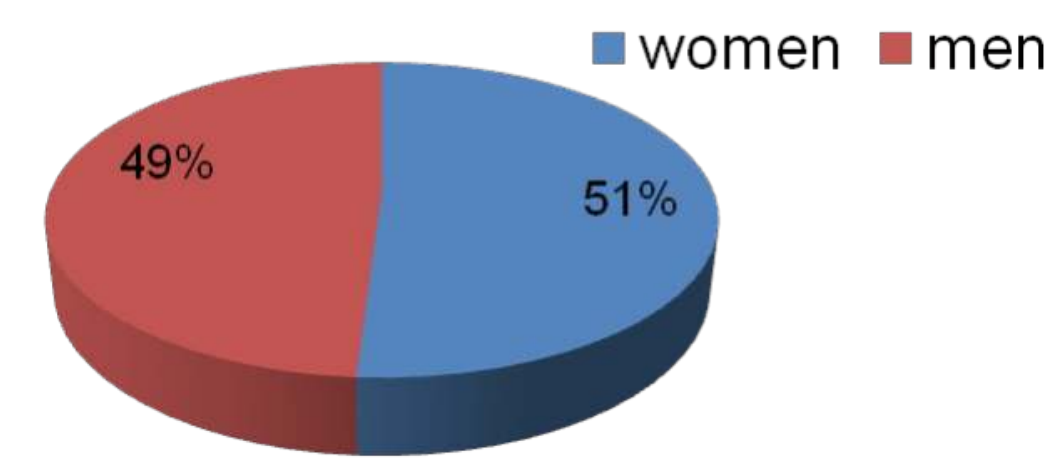

It was found that the age of patients with metformin therapy was $53,82 \pm 1,23$ years, duration of T2DM of these patients $5,29 \pm 0,58$, their body mass index- $34,36 \pm 0,95$, their average fasting plasma glucose before the treatment $-9,10 \pm 0,28$; level of patients' QOL before treatment was $0,69 \pm 0,03$, after the treatment $-0,80 \pm 0,03$. The age of patients with glimepiride therapy was $57,88 \pm 2,56$ years, duration of T2DM of these patients $-6,69 \pm 0,63$, their body mass index $-29,4 \pm 2,25$, the average fasting plasma glucose before the treatment $10,03 \pm 0,62$; level of patients' QOL before treatment was $0,42 \pm 0,03$, after the treatment $-0,50 \pm 0,04$. The age of patients with gliclazide therapy was $58,47 \pm 2,66$ years, duration of T2DM- 6,63 $\pm 1,43$, their body mass index $-27,48 \pm 1,66$, the average fasting plasma glucose before the treatment $9,81 \pm 0,57$; level of patients' QOL before the treatment was

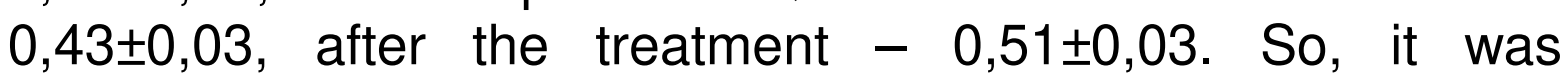
determined that the patients with metformin therapy were significantly younger, with the shortest T2DM duration, with the highest body mass index and lowest levels of fasting plasma glucose before the treatment; these patients had the highest level of QOL ( $p>0.05)$.

\section{Level of QOL}

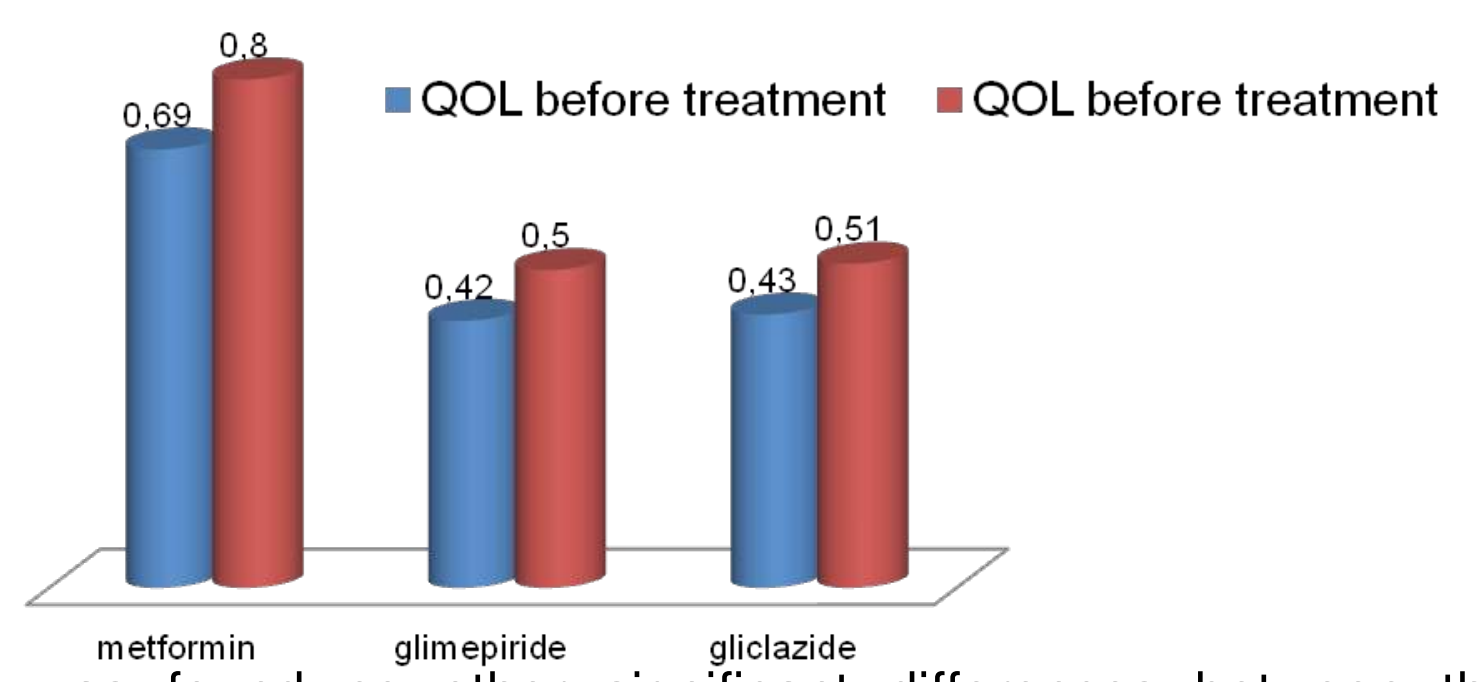

It was found no other significant differences between the patients with gliclazide and glimepiride regimes $(p>0.05)$. As a result of the survey by questionnaire, it was found that level of patients' QOL with metformin therapy before the treatment was $0,69 \pm 0,03$, after the treatment $-0,80 \pm 0,03 \quad(p<0.05)$; glimepiride $-0,42 \pm 0,03$ and $0,50 \pm 0,04$, respectively $(p<0.05)$; gliclazide $-0,43 \pm 0,03$ and $0,51 \pm 0,03$, respectively $(p<0.05)$.

\section{Conclusions}

The results of this study showed that the greatest value of QOL had patients with metformin therapy, the lowest - with glimepiride and gliclazide therapy. In patients who have been treated with metformin a positive effect on QOL was founded. The point of the Study was to discover the possibility of negative affect of diabetes mellitus on the patients' quality of life. When comparing patients who were exposed to man-made disaster (war in Ukraine, refugees, temporarily displaced persons, immigrants) and the common population, the negative impact of this factor on QOL in all groups was founded.

\section{Key words:}

type 2 diabetes mellitus, quality of life (QOL), EuroQol-5D 